antihypertensive, lipid-lowering and, although not always, aspirin. ${ }^{(8)}$

\section{References}

1. Zhou, B., Perel, P., Mensah, G.A. et al. Global epidemiology, health burden and effective interventions for elevated blood pressure and hypertension. Nat Rev Cardiol (2021).

2. Vrijens B, Vincze G, Kristanto P, Urquhart J, Burnier M. Adherence to prescribed antihypertensive drug treatments: longitudinal study of electronically compiled dosing histories.BMJ. 2008; 336:1114-1117. doi: 10.1136/ bmj.39553.670231.25

3. Hill MN, Miller NH, Degeest S, Materson BJ, Black HR, Izzo JL, Oparil S, Weber MA; American Society of Hypertension Writing Group. Adherence and persistence with taking medication to control high blood pressure.J Am Soc Hypertens. 2011; 5:56-63. doi: 10.1016/j. jash.2011.01.001

4. Adherence to Long-term Therapies Evidence for Action. Bulletin World Health Organization (WHO) 2003, 216 pages
5. Vrijens B, De Geest S, Hughes DA, Przemyslaw K, Demonceau J, Ruppar T, Dobbels F, Fargher E, Morrison V, Lewek P, Matyjaszczyk M, Mshelia C, Clyne W, Aronson JK, Urquhart J; ABC Project Team. A new taxonomy for describing and defining adherence to medications. Br J Clin Pharmacol. 2012; 73:691-705. doi: 10.1111/j.1365-2125.2012.04167.x

6. Burnier M, Egan BM. Adherence in Hypertension. Circ Res. 2019 Mar 29;124(7):1124-1140

7. Position Statement on Use of Pharmacological Combinations in a Single Pill for Treatment of Hypertension by Argentine Federation of Cardiology (FAC) and Argentine Society of Hypertension (SAHA). Renna NF, Piskorz D, Stisman D, Martinez D, Lescano L, Vissani S, Espeche W, Marquez D, Parodi D, Naninni D, Baroni M, Llanos D, Martinez R, Barochinner J, Staffieri G, Lanas F, Velásquez M, Marin M, Williams B, Ennis I. J Human Hyper 2021doi: 10.1038/s41371-021-00557-w

8. Muñoz D, Uzoije P, Reynolds C, Miller R, Walkley D, Pappalardo S, Tousey P, Munro H, Gonzales H, Song W, White C, Blot WJ, Wang TJ. Polypill for Cardiovascular Disease Prevention in an Underserved Population. N Engl J Med. 2019 Sep 19;381(12):1114-1123.

\title{
NEW BLOOD \\ Cardiorenal Syndrome: immune system as an intriguing connector between Heart and Kidney
}

\author{
CAROLINA VICTORIA CRUZ JUNHO \& MARCELA SORELLI CARNEI- \\ RO-RAMOS \\ Laboratory of Cardiovascular Immunology. Center of Natural and Human \\ Sciences (CCNH). Federal University of ABC. Santo André. SP. Brazil.
}

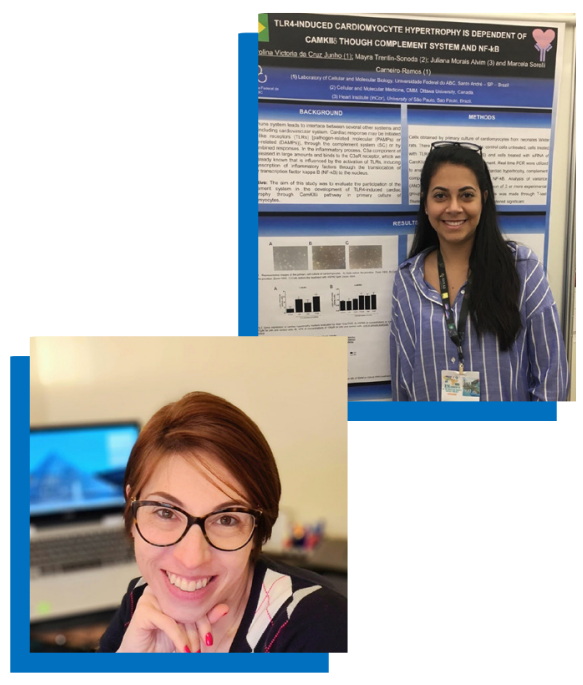

DOI:10.30824/2110-15

Since 1836 when Robert Bright first described the relationship between heart and kidneys, the scientific community has dedicated itself to better understanding the mechanisms involved in the kidney-heart axis, known in recent decades as cardiorenal syndrome (CRS) ${ }^{[1]}$. CRS can be classified into 5 different types, where types 1 and 2 are defined by acute or chronic cardiac alterations that lead to renal dysfunction, types 3 and 4 defined by acute or chronic renal alterations responsible for later cardiac alterations, and finally type 5 , characterized by concomitant dysfunctions of the kidneys and heart due to systemic alterations such as 
sepsis or diabetes ${ }^{[2]}$. CRS type 3 affects a large amount of the population and is defined by an acute renal alteration capable of generating important cardiac alterations ${ }^{[3]}$. The acute kidney injury (AKI) increases from $5 \%$ to $30-50 \%$ in all patients hospitalized in intensive care units and is present in $\sim 43 \%$ of all deaths related to cardiovascular diseases ${ }^{[4]}$. Ischemia and reperfusion (IR) injury is the main cause of AKI. This is a temporary condition that obstructs the blood flow in the kidney, leading to the release of oxidative stress compounds as well as inflammatory cytokines ${ }^{[5]}$. In this sense, our laboratory has been seeking to understand the cellular, molecular and functional mechanisms involved in cardiac alterations induced by AKI in an IR model in mice.

The AKI induced by the IR model leads to an inflammatory process that seems to be important to the development of heart dysfunction. One of the main focuses of our group was to evaluate the role of innate immunity, represented by Toll-Like receptors (TLRs), in cardiac

tropism modulated by acute kidney injury. First, we demonstrate that IR model are able to induce an acute systemic inflammation (until 8 days of reperfusion) followed by a concentric cardiac hypertrophy (after 15 days of reperfusion) not accompanied by fibrosis. Besides, TLRs 2 and 4 are essential for cardiac hypertrophy development observed in IR model ${ }^{[6]}$. In addition to cardiac hypertrophy and acute inflammation, it was possible to observe important electrical changes demonstrated to an increase on action potential duration (APD) and QTc interval [7].

The increased number of pro-arrhythmogenic events stimulated us to investigate the role of some inflammatory cytokines that were shown to be altered in this experimental model. Thus, we studied the role of NLRP3 inflammasome and IL-1b on arrhythmogenic events and we demonstrated, for the first time, that the inflammatory cytokine IL-1 b plays a crucial role in cardiac arrhythmia induced by acute kidney injury once knockout models and pharmacological interventions were able to prevent arrhythmogenic events ${ }^{[7]}$. Besides, other studies by our group have shown that the Renin-AngiotensinAldosterone System (RAAS) and the Sympathetic Nervous System (SNS) are important mediators of the kidney-heart axis since cardiac inflammatory events induced by renal IR, caused by the simultaneous upregulation of the SNS and RAAS in the heart, possibly support the mechanism involved in the development of cardiorenal syndrome ${ }^{[8]}$. Furthermore, it was possible to demonstrate that the IR model mimicking CRS3 presents a specific tissue and time regulation regarding the redox balance, which suggests possible forms of therapeutic interventions ${ }^{[9]}$.

Although some of the mediators of the conversation between kidneys and heart are known, much remains to be explored regarding the mechanisms involved in each type of CRS. Some of them we are currently studying as the participation of mitochondria dysfunction, modulation of lymphocytes and macrophages populations, accumulation of uremic toxins and extracellular vesicles content.

\section{References}

1. Bright, R. Cases and Observations Illustrative of Renal Disease, Accompanied with the Secretion of Albuminous Urine. Med Chir Rev. 1836, 25, 23-35.

2. Ronco, C.; Bellasi, A.; Di Lullo, L. Cardiorenal Syndrome: An Overview. Adv. Chronic Kidney Dis. 2018, 25, 382-390, doi:10.1053/j.ackd.2018.08.004.

3. Di Lullo, L.; Bellasi, A.; Barbera, V.; Russo, D.; Russo, L.; Di lorio, B.; Cozzolino, M.; Ronco, C. Pathophysiology of the cardio-renal syndromes types 1-5: An uptodate. Indian Heart J. 2017, 69, 255-265, doi:10.1016/j. ihj.2017.01.005.

4. Ronco, C.; Bellomo, R.; Kellum, J.A. Acute kidney injury. Lancet 2019, 394, 1949-1964.

5. Pieretti, J.C.; Junho, C.V.C.; Carneiro-Ramos, M.S.; Seabra, A.B. H2S- and NO-releasing gasotransmitter platform: A crosstalk signaling pathway in the treatment of acute kidney injury. Pharmacol. Res. 2020, 161, 105121, doi:10.1016/j.phrs.2020.105121.

6. Trentin-Sonoda, M.; Da Silva, R.C.; Kmit, F.V.; Abrahão, M.V.; Cahli, G.M.; Brasil, G.V.; Muzi-Filho, H.; Silva, P.A.; Tovar-Moll, F.F.; Vieyra, A.; et al. Knockout of toll-like receptors 2 and 4 prevents renal ischemia-reperfusioninduced cardiac hypertrophy in mice. PLoS One 2015, 10, 1-21, doi:10.1371/journal.pone.0139350.

7. Alarcon, M.M.L.; Trentin-Sonoda, M.; Panico, K.; Schleier, Y.; Duque, T.; Moreno-Loaiza, O.; de Yurre, A.R.; Ferreira, F.; Caio-Silva, W.; Coury, P.R.; et al. Cardiac arrhythmias after renal I/R depend on IL-1 $\beta$. J. Mol. Cell. Cardiol. 2019, 131, 101-111, doi:10.1016/j. yjucc.2019.04.025. 
8. Panico, K.; Abrahão, M. V.; Trentin-Sonoda, M.; Muzi-Filho, H.; Vieyra, A.; Carneiro-Ramos, M.S. Cardiac inflammation after ischemia-reperfusion of the kidney: Role of the sympathetic nervous system and the reninangiotensin system. Cell. Physiol. Biochem. 2019, 53, 587-605, doi:10.33594/000000159.
9. Caio-Silva, W.; da Silva Dias, D.; Junho, C.V.C.; Panico, K.; Neres-Santos, R.S.; Pelegrino, M.T.; Pieretti, J.C.; Seabra, A.B.; De Angelis, K.; Carneiro-Ramos, M.S. Characterization of the Oxidative Stress in Renal Ischemia/Reperfusion-Induced Cardiorenal Syndrome Type 3. Biomed Res. Int. 2020, 2020, 1605358, doi:10.1155/2020/1605358.

\section{tł STRIDE BP}

JOINT INITIATIVE WTIH
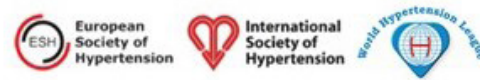

About us BP Monitors Training Literature

EN ES ZH

Q Search

Home / BP Monitors

Validated blood pressure monitors

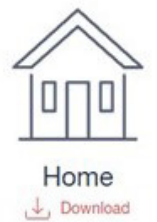

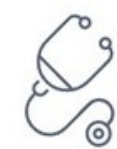

Office/Hospital $\downarrow$ Download

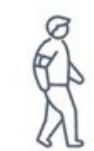

Ambulatory

$\downarrow$, Download

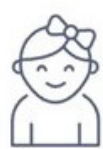

Children $\downarrow$ Download

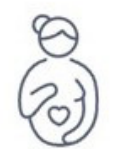

Pregnancy $\downarrow$ Download

\section{a:care congress 20-21 October 2021:}

The first congress exploring how to improve medication adherence through behavioral science.

- Join us to hear from world-renowned experts

- Learn about behavioral interventions and digital technology

- Collaborate with peers

\section{a:care}

THIS IS ADHERENCE REIMAGINED. This is care empowered.

REGISTER TODAY acarepro.abbott.com/en/congress 2021

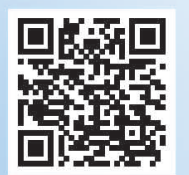

